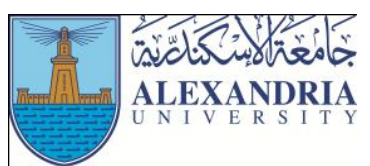

\title{
Strategic Map for the Balanced Performance as a Tool for Managing the Strategic Performance at the Egyptian Olympic Bodies in the Light of Thirty-First Session Results of Rio De Janeiro, Brazil, 2016 (Comparative Study)
}

\author{
Hussein Mohamed Abdel-haleem ${ }^{1}$, Mohamed Fathy Abdel-hafez ${ }^{2}$ \\ ${ }^{1}$ Assistant professor at sport administration, Faculty of physical education, Minia University, Egypt \\ ${ }^{2}$ Instructor at sport administration dep., Faculty of physical education, Minia University, Egypt
}

\begin{abstract}
The research aims to measure the strategic performance of the Olympic committees (Olympic Committee / Committee Paralympics), depending on the Balanced Scorecard, including the proposed conception for the strategic map of the balanced performance as a tool to manage the strategic performance of those Olympic committees. The researchers used the descriptive approach by "surveys," "analytical Comparative method"

The research community included the beneficiaries from the Olympic committees" Olympic Committee and Paralympics, represented in (ICRC staff, technical and administrative organs of the teams, players) and participation in the Olympic Games in the period (from5 to August 21, 2016) and participation in Paralympic Games in the period (from7 to 18September 2016) in Rio de Janeiro, Brazil, with a sample of (260) two hundred and sixty players. The sample of Olympic Committee was (192) one hundred ninety-two individuals as a percentage of (60.18\%), while the sample Paralympic Committee amounted to (68) eight and sixty members with a percentage of (60\%).
\end{abstract}

The researchers used a questionnaire based on the dimensions of the Balanced Scorecard aims to identify the level of performance of strategic Olympic committees (IOC / Paralympic Committee).

One of the most important results is the weakness of the strategic performance level in general Olympic committees (Olympic Committee / Committee Paralympics). Also that there are no statistically significant differences between the Olympic committees in the total degree of the questionnaire in the direction of (Paralympic Committee). Reaching to the proposed conception for the strategic map of the balanced performance at the Olympic committees (Olympic Committee I Paralympic Committee) under discussion.

The most important recommendations to activate the proposed concept of strategic map of the balanced performance within the Olympic committees "under consideration" as a tool for managing the strategic performance, and try to circulate the idea to all the other sports bodies.

Introduction\& Research problem:

B alanced Scorecard is considered an important indicator of performance evaluation within the bodies. It is also one of the most important tools that can help in facing issues that relate to the process of the implementation of their strategic plans, where many research studies have shown that approximately between (70\% to $90 \%$ ) from bodies and institutions fail to implement their own strategic plans because of the problems associated with the low level of commitment and the strategic crowd, so the implementers apply the
Balanced Scorecard as a measurement system guiding the strategy as to contribute in solving the problem of connecting, managing and applying the strategy (Malkawi 2009: 57),(El Maher 26, 2007).

Through the interviews conducted by the researchers with some officials within the Olympic bodies, they found that there is an absence of indicators of the strategic performance measurement and weakness in the strategic orientation for its administration, as it is always being planning for a sports event or participation for short term without considering the returns that can be gained with the strategic planning for those sporting events, as evidenced 
by what happened in the recent Olympic Games in Brazil cycle during the period from (5 to 12 August, 2016), which Egypt participated in with (122) athletes with the biggest mission in its history and has spent the amount of 130 million pounds of equivalent to 13 million dollars to reap medals, which Egypt got just (3) bronzes as well also in the Paralympic Games (Olympics with special needs) during the period from (7 to 18 September, 2016) in

Table (1)

Results of Egypt in the Olympic and Paralympic Games during the historical period from (1988 to 2016)

\begin{tabular}{|c|c|c|c|c|c|c|c|c|}
\hline \multirow[t]{2}{*}{ Game } & \multirow[t]{2}{*}{ year } & \multirow[t]{2}{*}{ Committee } & \multirow{2}{*}{$\begin{array}{c}\text { Participated } \\
\text { countries }\end{array}$} & \multicolumn{4}{|c|}{$\begin{array}{l}\text { Number of medals Egypt have obtained\& } \\
\text { its type }\end{array}$} & \multirow{2}{*}{$\begin{array}{c}\text { The genera } \\
\text { arrange of } \\
\text { Egypt }\end{array}$} \\
\hline & & & & Gold & silver & bronze & total & \\
\hline \multirow{2}{*}{ SEOUL, Korea } & \multirow{2}{*}{1988} & Paralympic & 60 & 1 & 2 & 5 & 8 & 35 \\
\hline & & Olympic & 159 & - & - & - & - & 0 \\
\hline \multirow{2}{*}{ Barcelona, Spain } & \multirow{2}{*}{1992} & Paralympic & 83 & 7 & 6 & 7 & 20 & 19 \\
\hline & & Olympic & 169 & - & - & - & - & 0 \\
\hline \multirow{2}{*}{ Atlanta American } & \multirow{2}{*}{1996} & Paralympic & 104 & 8 & 11 & 11 & 30 & 21 \\
\hline & & Olympic & 197 & - & - & - & - & 0 \\
\hline \multirow{2}{*}{ Sydney, Australia } & \multirow{2}{*}{2000} & Paralympic & 122 & 6 & 12 & 10 & 28 & 23 \\
\hline & & Olympic & 199 & - & - & - & - & 0 \\
\hline \multirow{2}{*}{ Athens Greece } & \multirow{2}{*}{2004} & Paralympic & 135 & 6 & 9 & 8 & 23 & 24 \\
\hline & & Olympic & 202 & 1 & 1 & 3 & 5 & 46 \\
\hline \multirow{2}{*}{ BEIJING China } & \multirow{2}{*}{2008} & Paralympic & 140 & 4 & 4 & 12 & 20 & 29 \\
\hline & & Olympic & 204 & - & - & 1 & 1 & 80 \\
\hline \multirow{2}{*}{ London England } & \multirow{2}{*}{2012} & Paralympic & 164 & 4 & 4 & 6 & 14 & 36 \\
\hline & & Olympic & 204 & - & 2 & - & 2 & 58 \\
\hline \multirow{2}{*}{ Rio de Janeiro, Brazil } & \multirow{2}{*}{2016} & Paralympic & 161 & 3 & 5 & 4 & 12 & 30 \\
\hline & & Olympic & 205 & - & - & 3 & 3 & 75 \\
\hline
\end{tabular}

Through studying these results and processed them statistically, it was found that Egypt is always stable in the upper quartile in terms of arrangement, that means, it is one of the developed nations in sports with special needs. Also it is clear that Egypt is always also stable in the lower quartile in terms of arrangement, which means, it is one of the latest countries in the Olympic sports. Through analyzing the previous table, it became clear that Egypt during the last eight Olympic circle won a (11) medals, while the Paralympic Committee won (155) medals, so these Olympic bodies should be taken care with to promte Egypt in this international sporting events.

Through access to many of the previous studies such as studying, "Abu al-Wafa 0.2014", "Mahmoud 0.2014", "Omar 2014", "hamid 2010", "Angham 2010", "Salem 2009", "ching 2009", "Zaghloul, 2008, "" Beauty 0.2007 "," Fouda 0.2005 , "Banker \& Pizzini, 2004" , "Abdul Mohsen .2015", "Khouly .2011", "Arif 2009"., "Moroccan, 2009" , "Salama, 2005" ," Kaplan \& Norton,1996, 2004,2005" .
Brazil, which Egypt participated in with (44) athletes, and earned (12) medal and has spent 61 million pounds.

The two researchers analyzed the results of Egypt through its participation in Olympic and Paralympic Games and preparing a documentary study for the results of Egypt during the historical period from (1988 to 2016), the results of Egypt were as follows:

The goal of research:

The research aims to develop a perception of a proposed strategic map for the balanced performance of Olympic committee (IOC / Paralympic Committee) at the Arab Republic of Egypt.

\section{Research questions}

1- What is the level of the strategic performance of the Olympic committees (IOC / Paralympic Committee), depending on the Balanced Scorecard?

2- Are there significant differences between the Olympic committees (Olympic Committee / Paralympic Committee) in the level of strategic performance depending on the Balanced Scorecard?

3-What is the perception of the proposed strategic map of the balanced performance at the Olympic committee (IOC / Paralympic Committee)? 


\section{Keywords:}

Strategic Map for balanced performance, strategic performance, Olympic committees.

\section{Research procedures:}

\section{Research Methodology:}

The researchers used the descriptive approach using "surveys"

\section{Society and the research sample:}

The research community in the beneficiaries of the Olympic committees (Olympic Committee / Paralympics committee) through participating in of the Olympic Games in the period from (5 to August 21, $2016 \mathrm{~m}$ ) and in Paralympic Games in the period from (7 to September 18, $2016 \mathrm{~m}$ ) in Rio de Janeiro, Brazil, consisted of (260) two hundred and sixty members as following and the table (2.3) clarify the research sample distribution (Appendix $5)$.

\section{Research tools:}

Survey strategic performance evaluation depending on the Balanced Scorecard (prepare researchers) (Appendix 6)

\section{Timetable for the search:}

The researchers conducted a prospective study in the period from $09 / 28 / 2016$ to $10 / 10 / 2016$ on a sample of (55) Fifty-five people, and then the researchers applied it on all the sample individuals "under discussion". The application period was from $15 / 10 / 2016$ to 13 / $11 / 2016$ on a sample of (260) two hundred and sixty people.

\section{Discussion and interpretation of the results:}

The answer to the first question : What is the level of the strategic performance at the Olympic committees (IOC / Paralympic Committee), depending on the Balanced Scorecard?

Table (2)

The relative weight and the response average for the questionnaire of the strategic performance level of the Olympic Committee depending on the Balanced Scorecard $(n=192)$

\begin{tabular}{|c|c|c|c|c|c|}
\hline \multirow{2}{*}{$\mathrm{N}$} & \multicolumn{3}{|c|}{ response } & \multirow{2}{*}{$\begin{array}{c}\text { Relative } \\
\text { weight }\end{array}$} & \multirow{2}{*}{$\begin{array}{l}\text { Response } \\
\text { Average }\end{array}$} \\
\hline & High & medium & low & & \\
\hline \multicolumn{6}{|c|}{ First dimension } \\
\hline 1 & 48 & 49 & 95 & 337 & 0,59 \\
\hline 2 & 6 & 20 & 166 & 224 & 0,39 \\
\hline 3 & 5 & 32 & 155 & 234 & 0,41 \\
\hline 4 & 57 & 36 & 99 & 342 & 0,59 \\
\hline 5 & 129 & 51 & 12 & 501 & 0,87 \\
\hline 6 & 8 & 32 & 152 & 240 & 0,42 \\
\hline 7 & 16 & 118 & 58 & 342 & 0,59 \\
\hline 8 & 36 & 71 & 85 & 335 & 0,58 \\
\hline 9 & 37 & 71 & 84 & 337 & 0,59 \\
\hline 11 & 49 & 42 & 101 & 332 & 0,58 \\
\hline 12 & 129 & 54 & 9 & 504 & 0,88 \\
\hline \multicolumn{4}{|c|}{ Relative weight average \& response average for the dimension as all } & 4057 & 0,59 \\
\hline \multicolumn{6}{|c|}{ second dimension } \\
\hline 13 & 137 & 46 & 9 & 512 & 0,89 \\
\hline 14 & 3 & 139 & 50 & 337 & 0,59 \\
\hline 15 & 3 & 130 & 59 & 328 & 0,57 \\
\hline 16 & 3 & 124 & 65 & 322 & 0,56 \\
\hline 17 & 5 & 139 & 48 & 341 & 0,59 \\
\hline 18 & 46 & 28 & 118 & 312 & 0,54 \\
\hline 19 & 11 & 31 & 150 & 245 & 0,43 \\
\hline 21 & 3 & 128 & 61 & 326 & 0,57 \\
\hline
\end{tabular}




\begin{tabular}{|c|c|c|c|c|c|}
\hline \multirow{2}{*}{$\mathrm{N}$} & \multicolumn{3}{|c|}{ response } & \multirow{2}{*}{$\begin{array}{c}\text { Relative } \\
\text { weight }\end{array}$} & \multirow{2}{*}{$\begin{array}{c}\text { Response } \\
\text { Average }\end{array}$} \\
\hline & High & medium & low & & \\
\hline \multicolumn{6}{|c|}{ First dimension } \\
\hline 22 & 3 & 142 & 47 & 340 & 0,59 \\
\hline 23 & 3 & 137 & 52 & 335 & 0,58 \\
\hline 24 & 16 & 36 & 140 & 260 & 0,45 \\
\hline \multicolumn{4}{|c|}{ Relative weight average $\&$ response average for the dimension as all } & 4182 & 0,61 \\
\hline \multicolumn{6}{|c|}{ third dimension } \\
\hline 25 & 20 & 75 & 97 & 307 & 0,53 \\
\hline 26 & 36 & 47 & 109 & 311 & 0,54 \\
\hline 27 & 33 & 48 & 111 & 306 & 0,53 \\
\hline 28 & 35 & 52 & 105 & 314 & 0,55 \\
\hline 29 & 92 & 49 & 51 & 425 & 0,74 \\
\hline 30 & 33 & 70 & 89 & 328 & 0,57 \\
\hline 31 & 39 & 55 & 98 & 325 & 0,56 \\
\hline 32 & 90 & 46 & 56 & 418 & 0,73 \\
\hline 33 & 20 & 67 & 105 & 299 & 0,52 \\
\hline 34 & 34 & 75 & 83 & 335 & 0,58 \\
\hline 35 & 37 & 62 & 93 & 328 & 0,57 \\
\hline 36 & 13 & 45 & 134 & 263 & 0,46 \\
\hline 37 & 29 & 54 & 109 & 304 & 0,53 \\
\hline 38 & 5 & 40 & 147 & 242 & 0,42 \\
\hline \multicolumn{4}{|c|}{ Relative weight average \& response average for the dimension as all } & 4505 & 0,56 \\
\hline \multicolumn{6}{|c|}{ fourth dimension } \\
\hline 39 & 6 & 50 & 136 & 254 & 0,44 \\
\hline 40 & 10 & 15 & 167 & 227 & 0,39 \\
\hline 41 & 4 & 12 & 176 & 212 & 0,37 \\
\hline 42 & 12 & 48 & 132 & 264 & 0,46 \\
\hline 43 & 23 & 43 & 126 & 281 & 0,49 \\
\hline 44 & 116 & 53 & 23 & 477 & 0,83 \\
\hline 45 & 38 & 22 & 132 & 290 & 0,50 \\
\hline 46 & 27 & 44 & 121 & 290 & 0,50 \\
\hline 47 & 36 & 32 & 124 & 296 & 0,51 \\
\hline 48 & 20 & 38 & 134 & 270 & 0,47 \\
\hline 49 & 132 & 37 & 23 & 493 & 0,86 \\
\hline 50 & 16 & 64 & 112 & 288 & 0,50 \\
\hline 51 & 23 & 69 & 100 & 307 & 0,53 \\
\hline \multicolumn{4}{|c|}{ Relative weight average\& response average for the dimension as all } & 3949 & 0,53 \\
\hline \multicolumn{4}{|c|}{ Relative weight average\& response average for the questionnaire as all } & 16693 & 0,57 \\
\hline
\end{tabular}

Table(2) shows that the response averages of the opinions of beneficiaries sample of the Olympic Committee in a questionnaire strategic performance phrases ranged between (0.37: 0.91$)$, as the response average of the first dimension "financial dimension" was (0.59), for the second dimension "customers (beneficiaries)." was (0.61), the third dimension " internal processes" was (0.56), and the fourth dimension " learning and growth" was $(0.53)$; while the average response to the questionnaire as a whole was (0.57). This shows the lack of all the responding averages to the dimensions of the questionnaire and the total degree as an indicator of the strategic performance of the Olympic Committee, except the second dimension "customers" as it came between the minimum and maximum trust. It means that it achieved moderately as an indicator of the strategic performance of the Olympic Committee. 
Table (3)

The relative weight and the response average for the questionnaire of the strategic performance level of the Paralympic Committee depending on the Balanced Scorecard $(n=68)$

\begin{tabular}{|c|c|c|c|c|c|}
\hline \multirow{2}{*}{$\mathrm{N}$} & \multicolumn{3}{|c|}{ response } & \multirow{2}{*}{$\begin{array}{c}\text { Relative } \\
\text { weight }\end{array}$} & \multirow{2}{*}{$\begin{array}{l}\text { Response } \\
\text { Average }\end{array}$} \\
\hline & High & medium & low & & \\
\hline \multicolumn{6}{|c|}{ First dimension } \\
\hline 1 & 28 & 35 & 5 & 159 & 0,78 \\
\hline 2 & 0 & 22 & 46 & 90 & 0,44 \\
\hline 3 & 5 & 7 & 56 & 85 & 0,42 \\
\hline 4 & 33 & 29 & 6 & 163 & 0,80 \\
\hline 5 & 5 & 21 & 42 & 99 & 0,49 \\
\hline 6 & 6 & 21 & 41 & 101 & 0,50 \\
\hline 7 & 9 & 18 & 41 & 104 & 0,51 \\
\hline 8 & 0 & 28 & 40 & 96 & 0,47 \\
\hline 9 & 16 & 0 & 52 & 100 & 0,49 \\
\hline 10 & 0 & 41 & 27 & 109 & 0,53 \\
\hline 11 & 3 & 30 & 35 & 104 & 0,51 \\
\hline 12 & 10 & 19 & 39 & 107 & 0,52 \\
\hline \multicolumn{4}{|c|}{ Relative weight average \& response average for the dimension as all } & 1317 & 0,54 \\
\hline \multicolumn{6}{|c|}{ second dimension } \\
\hline 13 & 24 & 44 & 0 & 160 & 0,78 \\
\hline 14 & 22 & 11 & 35 & 123 & 0,60 \\
\hline 15 & 32 & 29 & 7 & 161 & 0,79 \\
\hline 16 & 27 & 39 & 2 & 161 & 0,79 \\
\hline 17 & 43 & 24 & 1 & 178 & 0,87 \\
\hline 18 & 33 & 29 & 6 & 163 & 0,80 \\
\hline 19 & 46 & 5 & 17 & 165 & 0,81 \\
\hline 20 & 60 & 3 & 5 & 191 & 0,94 \\
\hline 21 & 34 & 29 & 5 & 165 & 0,81 \\
\hline 22 & 17 & 24 & 27 & 126 & 0,62 \\
\hline 23 & 28 & 39 & 1 & 163 & 0,80 \\
\hline 24 & 20 & 23 & 25 & 131 & 0,64 \\
\hline \multicolumn{4}{|c|}{ Relative weight average $\&$ response average for the dimension as all } & 1887 & 0,77 \\
\hline \multicolumn{6}{|c|}{ third dimension } \\
\hline 25 & 4 & 43 & 21 & 119 & 0,58 \\
\hline 26 & 11 & 17 & 40 & 107 & 0,52 \\
\hline 27 & 29 & 39 & 0 & 165 & 0,81 \\
\hline 28 & 11 & 9 & 48 & 99 & 0,49 \\
\hline 29 & 6 & 44 & 18 & 124 & 0,61 \\
\hline 30 & 2 & 40 & 26 & 112 & 0,55 \\
\hline 31 & 0 & 49 & 19 & 117 & 0,57 \\
\hline 32 & 18 & 20 & 30 & 124 & 0,61 \\
\hline 33 & 2 & 50 & 16 & 122 & 0,60 \\
\hline 34 & 11 & 40 & 17 & 130 & 0,64 \\
\hline 35 & 35 & 32 & 1 & 170 & 0,83 \\
\hline 36 & 13 & 24 & 31 & 118 & 0,58 \\
\hline 37 & 8 & 40 & 20 & 124 & 0,61 \\
\hline 38 & 5 & 32 & 31 & 110 & 0,54 \\
\hline \multicolumn{4}{|c|}{ Relative weight average $\&$ response average for the dimension as all } & 1741 & 0,61 \\
\hline
\end{tabular}




\begin{tabular}{|c|c|c|c|c|c|}
\hline \multirow{2}{*}{$\mathrm{N}$} & \multicolumn{3}{|c|}{ response } & \multirow{2}{*}{$\begin{array}{c}\text { Relative } \\
\text { weight }\end{array}$} & \multirow{2}{*}{$\begin{array}{c}\text { Response } \\
\text { Average }\end{array}$} \\
\hline & High & medium & low & & \\
\hline \multicolumn{6}{|c|}{ First dimension } \\
\hline \multicolumn{6}{|c|}{ fourth dimension } \\
\hline 39 & 6 & 15 & 47 & 95 & 0,47 \\
\hline 40 & 0 & 11 & 57 & 79 & 0,39 \\
\hline 41 & 40 & 14 & 14 & 162 & 0,79 \\
\hline 42 & 0 & 32 & 36 & 100 & 0,49 \\
\hline 43 & 7 & 23 & 38 & 105 & 0,51 \\
\hline 44 & 1 & 31 & 36 & 101 & 0,50 \\
\hline 45 & 6 & 17 & 45 & 97 & 0,48 \\
\hline 46 & 11 & 4 & 53 & 94 & 0,46 \\
\hline 47 & 13 & 11 & 44 & 105 & 0,51 \\
\hline 48 & 5 & 27 & 36 & 105 & 0,51 \\
\hline 49 & 38 & 22 & 8 & 166 & 0,81 \\
\hline 50 & 11 & 9 & 48 & 99 & 0,49 \\
\hline 51 & 8 & 13 & 47 & 97 & 0,48 \\
\hline \multicolumn{4}{|c|}{ Relative weight average \& response average for the dimension as all } & 1405 & 0,53 \\
\hline \multicolumn{4}{|c|}{ Relative weight average\& response average for the questionnaire as all } & 6350 & 0,61 \\
\hline \multicolumn{6}{|c|}{ The minimum limit for trust $=0,56$} \\
\hline
\end{tabular}

Table (3) shows that the Response averages of the opinions of beneficiaries sample of the Paralympic Committee in a questionnaire strategic performance phrases ranged between (0.39: 0.94), as the response average of the first dimension "financial dimension" was (0.54), for the second dimension "customers (beneficiaries)." was (0.77), the third dimension " internal processes" was $(0.61)$, and the fourth dimension " learning and growth" was (0.53); while the average response to the questionnaire as a whole was (0.61). This shows the lack of all the responding averages to the dimensions of the questionnaire and the total degree as an indicator of the strategic performance of the Olympic Committee, except the second dimension "customers" as it came between the minimum and maximum trust. It means that it achieved moderately as an indicator of the strategic performance of the Olympic Committee

the researchers attribute that result to the weakness of the efforts made by those in charge of Olympic Committee management in which it achieves its goals and makes them able to carry out its duties and functions associated with the Olympic and international competitions in order to achieve the achievements in international affairs globally, Olympia , continental and regional levels, as well as the failure of the administration of the Olympic Committee to develop a strategy own and implement it. As well as the evaluation and measurement process were based on subjective and lacks the scientific and substantive criteria, as seen results only as an indicator or criterion for success. It means that the assessment is done by focusing on only one side and the omission of many important aspects; this is consistent with (Abu al-Wafa et al., 2014) and (elgamal, 2007) studies.

Answering the second question which states: Are there significant differences between the Olympic committees (Olympic Committee / Paralympic Committee) in the level of strategic performance depending on the Balanced Scorecard? 
Table (4)

Statistical significance differences between Olympic bodies (Olympic Committee, Paralympic

Committee) in the level of strategic performance depending on the Balanced Scorecard $(n=260)$

\begin{tabular}{|c|c|c|c|c|c|c|}
\hline \multirow[t]{2}{*}{ dimensions } & \multicolumn{2}{|c|}{$\begin{array}{l}\text { Olympic Committee } \\
\qquad \mathrm{N}=192\end{array}$} & \multicolumn{2}{|c|}{$\begin{array}{c}\text { Paralympic Committee } \\
\mathrm{N}=68\end{array}$} & \multirow[t]{2}{*}{ T value } & \multirow[t]{2}{*}{ Direction } \\
\hline & M & A & M & A & & \\
\hline First dimension: financial & 21,13 & 4,36 & 19,37 & 1,44 & 4,89 & Olympic \\
\hline Second dimension: customers & 21,78 & 1,62 & 27,75 & 2,41 & 18,97 & Paralympic \\
\hline Third dimension: Internal Processes & 24,09 & 5,71 & 25,60 & 2,19 & 3,08 & Paralympic \\
\hline Fourth dimension: Learning\& Growth & 20,57 & 4,91 & 20,66 & 2,26 & 0,21 & No differences \\
\hline Strategic performance as whole & 87,57 & 13,21 & 93,38 & 5,62 & 4,96 & Paralympic \\
\hline
\end{tabular}

The value of tabled $(\mathrm{T})$ at free degree $(258)$ and the level of significance $(0.05)=1,960$

Table (4) show that there are significant differences between the (Olympic Committee, Paralympic Committee) in the first dimension of the questionnaire for the strategic performance level, depending on the Balanced Scorecard in the direction of (IOC), and there are significant differences between the (Olympic Committee, Paralympic Committee) in each of the (the second dimension, the third and the total degree) of the questionnaire for the strategic performance level, depending on the balanced Scorecard in the direction of (Paralympic Committee). While there is non-significant differences between the (Olympic Committee, Paralympic Committee) in the fourth dimension of the questionnaire for the strategic performance level, depending on the balanced Scorecard.

The researchers attributed the outcomes relating to the first dimension (financial dimension) to the lack of Paralympic Committee for a financial strategy about how to provide sources of funding Resume and financial resources for the implementation of public policies relating to the conduct of work to induce the development of competitive sport away from government support. It leads to the disposal of the risks of relying on source support which is the state. Thus its independence in making decisions and achieve the principle of self-management in their affairs will only be achieved by providing the means for self-development resources.

The researchers attributed the outcome of the second dimension (customers) to weakness of the Olympic Committee to determine the beneficiaries accurately, and thus unable to find out their needs and try to satisfy them by providing activities and services consistent with the size and nature of their desires achieving a degree of balance between the activities and the available services. It is lack the ability to deal with the beneficiaries as the first pivot point from which they develop its performance. As well as the weakness of attention to the provided services and activities. So the total does not rise to the level of the required performance to compete in sporting circles. This result is considered actually an indication of lower-level competitive both on local or international level. This refers to the inability of people at the institution to create a competitive environment suitable with the level and size of the needs of the beneficiaries within the Olympic Committee

The researchers attribute the outcome relating to the third dimension (internal operations) to the weakness of the factors related to work procedures, and the weakness of the efforts made by those who work on the Olympic Committee by the way that achieves its goals and makes them able to carry out its duties and functions associated with the competitions for achieving the accomplishments in the international affairs globally, Olympia, continentally and regionally, as well to the failure of those in charge of administration in developing its strategy and implementing it. As well as the methods used in the measurement and evaluation are traditional and rely on self-criteria lacking the objectivity scientific standards.

The researchers attribute the result of the fourth dimension (learning and growth) to the limited attempts by the Olympic and Paralympics committee to improve the performance of human resources through providing some training programs and courses but they does not meet the needs of the beneficiaries of the human resources in size and species, which requires managing and training of the available human resources that may contribute to improve the strategic performance.

Answering the third question which states on: What is the perception of the proposed strategic map of the balanced performance at the Olympic committee (IOC / Paralympic Committee)? (Appendix 7) 


\section{Conclusions:}

1- Weakness of strategic performance in general at the level of the Olympic committees

2-There are statistically significant differences between the Olympic committees in total degree of the questionnaire in the direction of (the Paralympic Committee).

3- Use strategy maps based on the Balanced Scorecard model may contribute in developing the strategic performance management of the Olympic committees " under consideration".

\section{Recommendations:}

1- Activate the proposed conception of the strategic map for the balanced performance within the Olympic committees" under consideration" as a tool for the management of strategic performance, and try to circulate the idea to all the other sports bodies.

2- Spread the culture of the Balanced Scorecard and strategy maps as a mechanism for the managing the strategic performance within the various sports bodies.

3- Prepare, qualify and train those who work on how to use the Balanced Scorecard and strategic maps in the work.

\section{References:}

\section{First, Arabic References:}

1- Malkawi, Ibrahim Alkhlof (2009): Strategic Performance Management using Balanced Scorecard, Warraq for Publishing and Distribution, Amman..

2- Almaher, Ahmed (2007): The scientific evidence for managers in Strategic Management, University House, Alexandria..

3- Abdul Mohsen, Mohammed Tawfiq (2015): Recent trends in the evaluation and distinction in management "Six Sigma and Balanced Scorecard", Dar Arab Thought, Cairo.

4- Abu al-Wafa, Jamal Mohammed et al. (2014): evaluating the Egyptian universities performance using the Balanced Scorecard, published research, Journal of the College of Education, the number (99) July c (2).

5- Zaghloul, Gouda Abdel Raouf (2008): Using the Balanced Scorecard scale in the construction of a system to measure the strategic performance in the Egyptian business environment, trade and finance magazine, Faculty of Commerce, Tanta University, n.1.

6- Omar, Ahmed Ceyhan (2014): the study of the impact of using the strategic map to model balanced performance on the effective implementation of the Strategic Plan of the Organization and competitive advantage (a field study on the joint banking sector), $\mathrm{PhD}$ Thesis, Sadat Academy for Management Sciences.

7- Mahmoud, Zainab Khairy (2014): Balanced performance measurement as a system for evaluating the performance of some service to youth and sports bodies, PhD Thesis, Faculty of Physical Education for Girls, Helwan University.

8- Fouda, Mr. Shawky (2005): A Proposed Framework to assess the strategic performance in modern production environment through the Balanced Scorecard scale, published research, the scientific journal (trade and finance), Faculty of Commerce, Tanta University.

9- Almaghraby, Abdel-Hamid Abdel Fattah (2009): Strategic Management measuring the Balanced Scorecard, Faculty of Commerce, Ain Shams University.

10- Salem, Imad Mosbah (2009): Evaluation of some Olympic sports federations using the Balanced Scorecard B.S.C system in the Arab Republic of Egypt, unpublished Master Thesis, Faculty of Physical Education for Boys, Helwan University.

11- Algamal, Amr Ahmed (2007): a proposed model for the management of the national Olympic federations using the Balanced Scorecard, published research, the scientific journal of Physical Education and Sports, No. (46), Faculty of Physical Education for Boys, Helwan University, Cairo.

12- Salama, Mohamed Mahmoud (2005): the strategic dimension to evaluate the Balanced Scorecard, the Arab Organization for Administrative Development, Cairo.

13- Alarif, Nadia (2009): Strategic Management "Third Millennium Management", University House, Alexandria..

14- Khouly, Hala Abdullah (2011): Using a balanced performance measurement model in the strategic performance measurement for businesses, Accounting and Management magazine, Faculty of Commerce, Cairo University.

\section{Second: English references:}

15- Banker, R. ,Change, H. \&Pizzini, M. (2004) : The Balanced Scorecard Judgment Effwcts of Performance Measures Linked To Strategy, The Accounting Review . 
16- B Rameshm, (2010) : Importance of Balanced scorecard for Growth of sme,Management accountant,vol.45,Iss.5.

17- Bieker,T,(2009) : Towards A sustainability Balanced scorecard Linking Environmental and social sustainability to Business strategy .

18- Ching, L. (2009): How Strategy Map Works For Ontario, s Health System, International Journal of Public Sector Management .Vol 22.Issue. 4.

19- Hamid,Tohidi,et,al,(2010) : using Balanced scorecard in educational organization, procedia - social and behaviora1scien. Issue 2 .

20- Ingham, J. (2010) : Using A human Capital Scorecard As Framework For Discovery, Stratigic HR Review .vol.10, Issue 2 .
21- Kaplan, R. \& Norton, D. (1996) : The Balanced Score Card: Translating strategy intoaction, Harvard Businen School Press, Boston .

22- Kaplan, R. \& Norton, D. (2001) : The strategy focused organization : how Balanced scorecard companies Thrive in The new Business Enviroment, Harvard Businen School Press, Boston .

23- Kaplan, R. \& Norton, D. (2004) : Strategy Maps, Converting Intangible Assets Into, Tangiple Outcomes, Harvard Business Press.

24- Kaplan, R. \& Norton, D. (2005) : The Office of Strategy Management, Strategic Finance Montvale, .vol.87, Iss 4

25- Oliver,P (2008) : Drauing up a Balanced scorecard for an integrated Quality,safety and environment cars system,Business globle Automotive manufacturing,vol3, Issue 4 . 